\title{
Theory and Practice of Simulation Experiment Teaching about the Electronic Sand Table in Enterprise
}

\author{
Yuanbing Liu ${ }^{1}$ and Wenbin Liu ${ }^{2, *}$ \\ ${ }^{1}$ Hunan University of Arts and Science, Hunan,415000, China \\ ${ }^{2}$ Wuhan Technology and Business University, Wuhan,430065,China \\ ( ${ }^{*}$ Corresponding Author: Wenbin Liu , email:812926096@qq.com)
}

\section{Keywords: Electronic Sand Table; Manage; Simulation experiment}

\begin{abstract}
Taking the experimental taching of the Electronic Sand Table for the Management of Information Management Specialty in Hunan University of Arts and Science as an example, the necessity and practical significance of the Electronic Sand Table experiment teaching is analyzed in the course of Enterprise Management. The process of developing the experiment teaching of the Electronic Sand Table is summarized. The experimental method is perfected. Firstly, the training and encouragement of experimental teaching teachers should be paid attention to. Secondly, the test software platform of the Electronic Sand Table should be perfected. Finally, auxiliary function of the manual sand table should be thought highly.
\end{abstract}

\section{Characteristics of Simulation Experiment of the Electronic Sand Table in Enterprise Operation}

The Electronic Sand Table simulation countermeasure system is a highly integrated system in enterprise operation. It involves the whole process of enterprise management, including enterprise planning, material purchasing, production arrangement, inventory management, marketing, financial control, human resource management, quality management, strategic support and decision making. In the simulation of the EW Sand Table in the omni-directional enterprise management, students experience basic business modules such as strategic decision-making, marketing planning, production process control, financial management, human resource management, etc. Students are deeply aware of basic management skills such as communication, conflict resolution, negotiation and motivation.

In the simulation process of the Electronic Sand Table confrontation, students carry out business in the role of enterprise manager, ensure the consistency between business and strategy, consciously apply theory to analyze the market, analyze consumer demand, and make product design decisions. Formulate marketing development and brand strategy, target market, develop and implement sales plan effectively. In teaching, when students are faced with the new and unknown situations set by teachers, they will have a strong sense of problem, which can directly stimulate the students undefined interest in learning.

The Electronic Sand Table simulation experiment of enterprise management simulation teaching system can not only aim at the comprehensive quality training of management, but also analyze and train some individual qualities in combination with the knowledge of management theory. The experimental teaching is conducted in groups. The enterprises composed of 5 -6 people in each group will be entrusted by the investment shareholders to run a start-up enterprise and enter the market competition. In a number of operating seasons, all participating business teams should maximize the value of the company as far as possible and maintain the enterprise development in the fierce competition with other groups.Students will play different management roles in the enterprise, such as general manager, marketing manager, production manager and financial manager, and try to make the enterprise survive and develop in the uncertain market environment. In the face of fierce market competition, team members must make many strategic decisions, such as market development, product development, equipment modification, cost control and so on, and implement them effectively. 


\section{The Experimental Teaching Organization of Electronic Sand Table in Enterprise Operation}

\section{Teaching Objectives and Hours Arrangement}

By simulating the business environment, students can imitate the operation process of the enterprise, promote the students to use the relevant management theory knowledge to effectively analyze the problems that appear in the enterprise management, evaluate the operation result, and improve the practical management thinking and the executive ability of the management. Students can improve their management skills and analysis, and solve practical problems. The Electronic Sand Table operating simulation experiment is arranged in the sixth semester as an independent teaching link. If a theoretical course as a complete experimental course, only with the main management courses can be synchronized.

\section{The Organization and implementation of Curriculum Content and Curriculum}

The Electronic Sand Table antagonism management experiment course includes the enterprise organization design, the strategic plan, the marketing plan, the market competition, the production management, the financial management and so on multi-functional domain knowledge content. The electronic sand table experiment course designs these knowledge in the software system practice operation process, deepens the student to the correlation management theory knowledge understanding.

\section{Experimental Preparation Stage}

The teacher forms practice groups of 4-6 students in each group. The teacher logs on to the Electronic Sand Table software platform, creates new classes and inputs students' information into the software platform. The Teacher gives students an introduction to the simulated business environment in the Electronic Sand Table counter platform, and data rules related to the operation of the simulation software. Students establish contacts with other team members. Students are familiar with the data rules and competitive environment of the simulated business environment. The students prepare the theoretical knowledge.

\section{Experimental Implementation Stage}

The students take the group as the unit, carry out the competitive management on the software experiment platform, make the important management decision in stages, and show the achievement of the stage of the management on the control platform of the teacher. After the completion of 8 business quarters, Comparing the operating conditions of various enterprises, the man who has the best combined results wins.

The Teacher should pay attention to the following two problems. First, after the end of each business quarter simulation operation, the business analysis chart is sent to students for the students to summarize after class. Second, the teacher expands the theory, concept, model difficulty, strengthens understanding and memory in the course of deepening business .

\section{The Teacher Comment and Students Summary Stage}

The teacher prints out the complete management decisions of each group of students, sends them to each group, and selects the group with the best operating results as a control. Students analyze business decision-making behavior in group, discuss in group, the group leader sums up. The guidance teacher carries on the appraisal and the summary to the key decision point, explains the decision point, strives to let the student be familiar with in the heart, achieves the goal of drawing a lesson from one another and reaching an analogy.

\section{Experiment Teaching Examination}

The internal capacity and weight of the examination are that attendance and actual schedule accounts for $20 \%$, experimental result accounts for $40 \%$, experimental report accounts for $30 \%$, experimental summary accounts for $10 \%$, full score is 100 . In the experiment examination, the teacher adopts the multi-angle appraisal method. All students are both participants and examiners. The content of the examination is aimed at both individual and team. The appraisal items and standards are clear. This has changed the way that it was completely graded by the instructor on the basis of the experimental report in the past. Through this kind of omni-directional experimental examination, the result of experiment is relatively objective and fair, and the degree of studentsundefined participation and approval is also high, which improves the enthusiasm and sense 
of responsibility of students to participate in the experiment, and is beneficial to the studentsundefined devotion to the experiment and the achievement of the purpose of the experiment.

\section{An Example of EW Operation Simulation System}

The teacher sets up basic system, students are grouped. the teacher publishs quarterly market forecasts via the server(The quarterly operation of an enterprise is a business cycle). The information includes the market capacity of the product, the guiding unit price, the developing trend of the market demand and so on . Each group develops business strategy and business strategy based on materials, and makes operational decisions according to the system steps under the leadership of group CEO. The effectiveness of decision-making reflects in the business results. The evaluation index includes five categories. The teacher can choose the weighted value of one type of index as the evaluation criterion, or the comprehensive value of all the indexes as the evaluation criterion. The weight of the index can be adjusted according to the purpose of the experiment. Through adjustment, the individual ability of students to run a business is cultivated. The Electronic Sand Table simulation integrates purchasing management, production management and quality management into production management field, and a series of decision-making is naturally presented to learners. Learners make full use of what they have learned, think positively, understand management knowledge in the process of simulating success and failure of management, improve management experience, and exercise management thinking.

\section{Proposition}

\section{Attention should be paid to the Training and Encouragement of Experimental Guidance Teachers}

First of all, the electronic sand table simulation experiment is completely different from the general experimental course. Its comprehensiveness and continuity are very strong, the complexity is very high, and the workload of preparation before class is very large. In the process of experiment simulation, the teacher has to answer the questions raised by the students and comment on them at each decision point. It takes a lot of energy to communicate and communicate with the students. Therefore, we should pay attention to the training of full-time experimental instructors. Secondly, according to the actual situation, the school should carry on the reasonable quantification on the workload verification, in order to ensure the enthusiasm of the guiding teachers, avoid the negative situation such as the experiment content is empty and the process is completely gameplay.

\section{Perfecting the Test Software platform of Electronic Sand Table}

In the course of the electronic sand table test, if the software rules are not recognized due to the instability of the system, and the operation interface is not friendly, the experiment process will be interrupted, which will not only affect the students' interest in participating, but also greatly reduce the effect of the experiment. Therefore, it is necessary to strengthen the contact with the software provider and feedback the information provided by the students in the experiment in order to perfect the system, such as operation rules, interface design, system stability, function operation, decision model, etc. Software providers are required to do a good job of after-sales service to promote the continuous improvement and improvement of the experimental software.

\section{To attach importance to the auxiliary function of the Manual Sand Table}

The experiment is dominated by the Electronic Sand Table and Manual Sand Table is used for some functions. On the one hand, in the Electronic Sand Table, most of the data operation and the relationship between the modules are finished by the computer, and the result is output directly on the display. Students did not participate in the calculation process and the production of some business charts in the software, and lost a perceptual understanding of the emergence of indicators such as market share, discount rate, and differences in depreciation methods. Students are often sceptical about the scientific nature of the final result of the Electronic Sand Table software, which affects the enthusiasm of participation. On the other hand, the experiment operation of the 
Electronic Sand Table only needs to input a number or a mouse point down menu through the keyboard, so that the discussion time left to the student is more. If this time is too long, it can result in too long waiting time between the decision nodes, which makes the participants feel bored and distracted. If the Manual Sand Table and the Electronic Sand Table are effectively combined, the experimental results will be greatly improved.

\section{Summary}

The electronic sand table experiment course adopts the international popular commercial simulation teaching technology, which can effectively solve the boring teaching model and the empty discussion content, so that students can deepen and consolidate their understanding and grasp of knowledge through personal participation and practical exercise under the guidance of teachers. Students participate in the team division of labor, strategic planning, market research, production planning, Research and development investment, sales management, market expansion, report analysis and other decisions in the simulated business environment. Understand all kinds of decision-making problems encountered in the operation of real enterprises, analyze and evaluate the results of operation effectively, thus have deeper experience and experience on various knowledge and skills in the management of enterprises. Finally, let them apply theoretical knowledge to practice in experiential learning, and effectively solve the problem of practical teaching for students majoring in management. If the experiment course of electronic sand table is used properly, it will effectively promote the teaching reform of management specialty in colleges and universities, and get rid of the problems of theorization and emptiness in the cultivation of management talents in colleges and universities. It provides an important way and mode for training applied talents to meet the market demand. It is theoretical and practical significance to study and summarize the new teaching method of simulation enterprise management Electronic Sand Table experiment teaching, which is theoretical and practical significance for exploring the practice of teaching process of management courses and the systematization of students' stress management thinking.

\section{Acknowledgments}

This research was supported by special subject of educational informatization of Higher Education Society in China (Grant No. 2016XXYB22).

\section{References}

[1] Youming Zhang. An Experimental study of the Teaching method of understanding in Tennis Teaching[J]. Journal of Mudanjiang normal University. 2010(1) 76-77.

[2] Xin Wang, Chuanyou Guo, Xianming Bao. Application of case Teaching in Environmental Management Teaching[J]. Journal of Mudanjiang normal University.2011(4) 78-79.

[3] Chunping Zhang. An Analysis of the Simulation training Mode of ERP Sand Table[J]. Journal of Kaifeng University. 2005(4) 32-33.

[4] Huijuan Zhao. Analysis of ERP Simulation course[J]. Chinese market.2010(1) 74-75.

[5] Yutao Song, Liying Ma. Discussion on the function and problems of ERP Sand Table Simulation course[J]. Experimental science and technology.2008(5)116-118.

[6] Xing S,Liu S,Sanf X,et al. Ground autostereoscopic display with new type non-uniform barrier[J]. Optik-International Journal for Light and Electron Optics.2016,127(13)5515-5519. 